Int. J. Electrochem. Sci., 15 (2020) 12380 - 12394

International Journal of

ELECTROCHEMICAL

SCIENCE

$\underline{\text { www.electrochemsci.org }}$

\title{
Effects of Polymeric Surfactant on the Self-Assembly of Bile salts
}

\author{
Naved Azum ${ }^{*}$, Mohammad Asad ${ }^{1}$, Malik Abdul Rub ${ }^{2}$, Abdullah M. Asiri ${ }^{1,2}$, Najam Sardar $^{3}$ \\ ${ }^{1}$ Chemistry Department, Faculty of Science, King Abdulaziz University, Jeddah 21589, Saudi Arabia \\ ${ }^{2}$ Center of Excellence for Advanced Materials Research, King Abdulaziz University, Jeddah 21589, \\ Saudi Arabia \\ ${ }^{3}$ Department of Petroleum Studies, Aligarh Muslim University, Aligarh-202002, India \\ *E-mail: navedazum@gmail.com
}

doi: $10.20964 / 2020.12 .34$

Received: 7 August 2020 / Accepted: 29 September 2020 / Published: 31 October 2020

The synergistic interactions between bile salts (BS) and the Pluronic block copolymer (P123) in aqueous solution at various mole fractions were investigated using the surface tension technique to explore the appropriate sequestrant (Pluronic P123) for bile salt. The interaction parameters in the bulk and surface were evaluated using ideal mixing and regular solution models. The synergistic effects operating in these amphiphile mixtures were confirmed by the negative values of the interaction parameter and reduction in critical micelle concentration $(\mathrm{cmc})$ values. Energetic parameters computed for bile salts and block copolymer mixtures were also discussed in detail.

Keywords: Bile salts, Pluronic, mixed micelle, synergism

\section{$\underline{\text { FULL TEXT }}$}

(C) 2020 The Authors. Published by ESG (www.electrochemsci.org). This article is an open access article distributed under the terms and conditions of the Creative Commons Attribution license

(http://creativecommons.org/licenses/by/4.0/). 